\title{
Chlorophyll Assessment and Sensitive Wavelength Exploration for Tea (Camellia sinensis) Based on Reflectance Spectral Characteristics
}

\author{
Xiao-li $\mathrm{Li}$ and Yong $\mathrm{He}^{1}$ \\ College of Biosystems Engineering and Food Science, Zhejiang University, \\ 268 Kaixuan Road, Hangzhou, Zhejiang 310029, China
}

Additional index words. chlorophyll index, tea, measurement, nondestructive, partial least squares, multiple linear regression

\begin{abstract}
A nondestructive method for the determination of chlorophyll index for the tea plant based on reflectance spectral characteristics was investigated. Spectral data were collected from 184 samples with a spectroradiometer in a field experiment. Multivariate analysis techniques, including partial least squares (PLS) and multiple linear regression (MLR), were used for developing calibration models for the determination of chlorophyll index of the tea plant. The best calibration model was achieved using the PLS technique with a correlation coefficient $(r)$ of 0.95 , a $\mathrm{SE}$ of prediction of 3.40 , and a bias of $1.9 \mathrm{e}^{-06}$. When the model was used for predicting the unknown samples, good performance was also obtained with $r$ of 0.91 , SE of calibration of 4.77 , and bias of 0.02 . Sensitive wavelengths were selected through loading analysis of latent variables in the optimal PLS model, and the validity of these wavelengths was proved by MLR and statistical analysis. Three fingerprint wavelengths $(488,695$, and $931 \mathrm{~nm})$ were determined and could potentially be used for developing a simple, low-cost, and efficient instrument for the measurement of chlorophyll index. The results proved the feasibility of reflectance spectra for measurement of chlorophyll index of the tea plant.
\end{abstract}

Nitrogen $(\mathrm{N})$ is an important nutrient for tea plant growth to obtain high yield or high quality. An adequate amount of $\mathrm{N}$ can accelerate the growth of tea plant, whereas excess $\mathrm{N}$ fertilizer may contaminate surface water and groundwater. Accurate assessment of $\mathrm{N}$ content of the tea plant is necessary for $\mathrm{N}$ fertilization.

Traditional methods for chlorophyll and $\mathrm{N}$ determination include soil testing, plant tissue analysis, and long-term field trials. Although these methods are accurate, they are destructive, time-consuming, and expensive. Portable nondestructive meters have been successfully used to determine foliar chlorophyll or N of many plants (Abdelhamid et al., 2003; Castelli et al., 1996; Loh et al., 2002; Schaper and Chacko, 1991; Yamamoto et al., 2002). Chlorophyll meters (e.g., SPAD-502, Minolta, Osaka, Japan) have been used to assess plant $\mathrm{N}$ status by measuring transmittance radiation through a leaf at two wavelengths centered near $650 \mathrm{~nm}$ and 940

\footnotetext{
Received for publication 5 Mar. 2008. Accepted for publication 20 Apr. 2008.

This study was supported by the National High-Tech Research and Development Plan (2007AA10Z210), Natural Science Foundation of China (Project No: 30671213), the National Science and Technology Support Program of China (2006BAD10A0711), and Science and Technology Department of Zhejiang Province (Project No. 2005C12029).

${ }^{1}$ To whom reprint requests should be addressed; e-mail yhe@zju.edu.cn
}

nm (Pinkard et al., 2006). Because the majority of foliar $\mathrm{N}$ is contained in chlorophyll molecules, a close relation between foliar chlorophyll content and foliar $\mathrm{N}$ content exists (Yoder and Pettigrew-Crosby, 1995). Foliar chlorophyll content is a good indicator of plant $\mathrm{N}$ status and photosynthesis activity (Chang and Robison, 2003). Leaf chlorophyll meter readings are generally linear with extractable chlorophyll contents for a wide variety of crops such as sugar maple leaves (van den Berg and Perkins, 2004), four species of hardwoods (Chang and Robison, 2003), and corn (Ulson et al., 2002). Furthermore, Song et al. (2002) studied the relationship between SPAD reading and chlorophyll content of fresh tea leaves and concluded that SPAD reading is correlated with chlorophyll content. Furthermore, high correlation exists between SPAD reading and ratio of chlorophyll a to chlorophyll $\mathrm{b}$.

Although the chlorophyll meter provides a relative $\mathrm{N}$ assessment without complex laboratory analysis, 15 or more readings are needed and averaged to get one measurement. Collecting the data of $\mathrm{N}$ content for large fields with spatial variations is a timeconsuming process using a chlorophyll meter (Daughtry et al., 2000). The measurement of leaf spectral reflectance using a spectrometer is a noncontact and nondestructive approach, and the scan time of one measurement can be less than $1 \mathrm{~s}$; it is a promising method for fast sensing of $\mathrm{N}$ status (Bausch and Duke, 1996; Tumbo et al., 2002). Bausch and Duke (1996) used a mobile system to acquire spectral data of corn and found that the $\mathrm{N}$ reflectance index had a good correlation $\left(r^{2}=\right.$ $0.81)$ with chlorophyll meter readings. Tumbo et al. (2002) assembled a spectrometer on a mobile tractor for fast measurement of chlorophyll index and found that spectral reflectance response patterns from a mobile sensor with speed of $0.6 \mathrm{~km} \cdot \mathrm{h}^{-1}$ could be used to predict chlorophyll in corn, and a strong relationship was obtained between near infra$\mathrm{red} /$ green $(\mathrm{NIR} / \mathrm{G})$ ratio and chlorophyll meter readings (in SPAD units). Several studies have shown that a direct relationship existed among spectral reflectance, chlorophyll content, and $\mathrm{N}$ status in green vegetation. Takebe et al. (1990) obtained a good correlation $\left(r^{2}=0.90\right)$ between the chlorophyll meter and spectral reflectance of rice. The spectrophotometer has been used to detect $\mathrm{N}$ content of cabbage seedling based on the reflectance spectra of leaves, and a good correlation $\left(r_{c}^{2}=0.89\right)$ was obtained with significant wavelengths $(566,574,1396$, and $1530 \mathrm{~nm}$ ) (Chen et al., 2004). Karimi et al. (2005) found a high accuracy of discrimination using hyperspectral reflectance spectra for plots with different $\mathrm{N}$ treatments. Min and Lee (2005) developed a N sensor for citrus trees based on diffuse reflectance of leaf samples; their calibration models showed a strong relationship between actual $\mathrm{N}$ concentration and reflectance spectra of citrus. For another economically important plant, tea, Hu et al. (2006) investigated the relationship between spectral reflectance and chlorophyll meter reading of fresh tea leaf and concluded that it was applicable to detect chlorophyll index based on reflectance spectra. However, the correlation coefficient was relatively low and the measurement SE was large. At the same time, Ishikawa et al. (2006) focused on the determination of chlorophyll of the tea plant by spectral image; they concluded that spectral image made it possible to study differences of growth stage of the tea plant. However, spectral image analysis is more complex compared with the reflectance spectra technique.

In this study, the relationship between visible/near infrared (Vis/NIR) reflectance spectral characteristics of tea plant and chlorophyll index was studied, and more attention was focused on evaluating the performance of calibration models, selecting the proper data pretreatment method, and exploring sensitive wavelengths. The specific objectives were: 1) to evaluate the potential of reflectance spectral characteristics for determining the chlorophyll index of six tea cultivars with a portable spectrophotometer; 2) to explore an effective pretreatment method to enhance the signal-to-noise and reduce noise caused by field environment; and 3) to seek the optimum sensitive wavelengths that are strongly related with the chlorophyll index of the tea plant.

\section{Materials and Methods}

Six cultivars of tea plants were selected for this experiment, including $C$. sinensis cv. Jiukeng (JK), C. sinensis cv. Biyun (BY), 
C. sinensis cv. Juhuaxiang (JH), C. sinensis cv. Lvyafoshou (LY), C. sinensis cv. Meizhan (MZ), and $C$. sinensis cv. Zhenghedabaicha $(\mathrm{ZH})$. The samples of the six cultivars were planted in the Seed Resource Garden of $120.19^{\circ}$ E, lat. $30.26^{\circ} \mathrm{N}$ ), China. These cultivars were planted at two blocks with three cultivars in each block. Within each block, three cultivars were planted in adjacent rows. The physiological age of these plants is $\approx 30$ years, the soil is red loam, and all the tea plants were treated with the same level of $\mathrm{N}$ fertilizer $\left(90 \mathrm{~kg} \cdot \mathrm{ha}^{-1}\right.$ urea $)$. One hundred eighty-four leaves (samples) were randomly selected from $\approx 60$ tea plants and approximately three samples, which were close to the top of the plant were pricked off from each plant. To add the diversity of samples, leaves with different physiological ages were taken into the experiment. The detailed information about the six cultivars is presented in Table 1.

On 20 April and 23 May in 2006, the field experiment was conducted. Reflectance spectra were acquired from 930 to 1630 under clear sky conditions using a field spectroradiometer (Fieldspec HandHeld; Analytical Spectral Devices, Boulder, CO) with 3.5-nm full-width-half-maximum spectral resolution and wavelength range from 325 to $1075 \mathrm{~nm}$. The spectroradiometer was stabilized on a tripod with $45^{\circ}$ angle between the spectroradiometer and the horizontal line. The spectroradiometer was set up at $\approx 100 \mathrm{~mm}$ above the surface of the leaf sample with a $10^{\circ}$ field of view. Sun was the light source. The zenith and azimuth angle of the sun changed during the experiment period, from $0^{\circ}$ to $90^{\circ}$ and from $-180^{\circ}$ to $180^{\circ}$, respectively. To reduce the effect of solar radiation intensity variation, the spectroradiometer was calibrated every half hour by a 100$\mathrm{mm}^{-2}$ optical reference standard panel with $\approx 100 \%$ reflectance across the entire spectrum. Reflectance was computed with measurements from both the leaf sample and a reference standard panel. For each sample, a mean spectrum was averaged by 60 scans. The reflectance spectra of all samples were transformed to absorbance $[\log (1 / \mathrm{R})]$ values according to Beer-Lambert law (Williams and Norris, 2001). Typical absorbance spectra of samples were shown in Figure 1. The first 75 and the last 75 wavelengths values were cut off as a result of significant noise observed, and all analyses were based on the range of wavelengths between 400 and 1000 $\mathrm{nm}$. After spectra measurement, the relative chlorophyll content was determined by a Tea Plant in Zhejiang University (long.

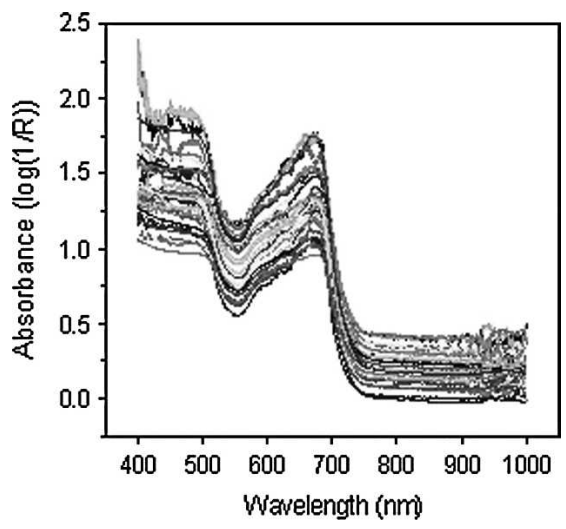

Fig. 1. Typical absorbance spectra of fresh tea leaves.

Minolta SPAD-502 (Minolta, Osaka, Japan) chlorophyll meter. The SPAD sensor was clipped on leaf mesophyll tissue instead of veins. Thirty measurements were taken per sample and averaged to provide a single chlorophyll index.

To test the influences of pretreatment methods on the performance of the calibration models, several types of pretreatments were used, including smoothing, standard normal variate, multiplicative scatter correction, derivatives, and offset (Candolfi et al., 1999). These pretreatments and calculations were carried out using The Unscrambler V9.2 (Camo, Process, AS, Oslo, Norway), a statistical software package for multivariate calibration.

All 184 spectra were divided into training set and prediction set. To avoid bias in subset selection, all samples were sorted according to their respective $Y$-value (chlorophyll index), then one of three samples were selected as the prediction set, resulting in 124 spectra of training set and 60 spectra of prediction set with $\approx 2: 1$ division (Table 2 ). The range of $Y$-value in the training set covered the range of that in the prediction set; therefore, the distribution of the samples was appropriate in the training set and prediction set.

Partial least squares (PLS) is a very powerful and classical multivariate analysis technique in chemometrics (Gomez et al., 2006; Lammertyn et al., 1998; Min and Lee, 2005; Zou et al., 2007). Compared with multiple linear regression (MLR), the advantage of PLS is that it is a bilinear modeling method in which the original $X$ (predictor variables) is projected onto a small number of orthogonal latent variables (LVs) to simplify the relationship between $X$ and $Y$ (response variables) (Lattin et al., 2003) and mitigate the colinearity problem (Helland, 2001; Min and Lee, 2005). In contrast to principal component regression (PCR), the selection of LVs in PLS is more rational. In detail, PCR chooses LVs with the maximum variance in $X$ but does not consider the $Y$, but the PLS method balances the two aspects and seeks the LVs that explain both $X$ and $Y$. The optimal number of LVs was generally chosen when the minimum of predicted residual error sum of squares (PRESS) value was obtained using full crossvalidation. The PRESS value was the sum of the squared difference between actual and predicted concentrations (during crossvalidation) (Madan et al., 2005). In this study, PLS regression was adopted on the full spectra (400 to 1000 $\mathrm{nm})$ of all 184 samples to explore the relationship between reflectance spectral characteristic and chlorophyll index.

The MLR model is a linear combination of $X$ variable that corresponds as closely as possible to the $Y$ variable (Lattin et al., 2003). Comparing with PLS and PCR, the drawback of MLR is that the number of samples for MLR must be greater than the number of variables (Madan et al., 2005), and the possible correlation among $X$ variables cannot be eliminated. The advantage of MLR is that a direct, simple, and clear relationship between $X$ and $Y$ can be obtained through MLR analysis. In this study, a small number of sensitive wavelengths from PLS analysis were set as predictor variables $(X)$, and the size of these variables was much smaller than that of samples. The MLR model was used to build a direct, simple, and linear formula between $X$ and $Y$.

The performances of the PLS and MLR models were evaluated by the SE of calibration (SEC), the SE of prediction (SEP), and the correlation coefficient $(r)$ between the actual and predicted concentration. For SEC, a leave-one-sample-out crossvalidation was performed. A good model should have a low SEC, a low SEP, a high $r$, and also a small difference between SEC and SEP. A large difference indicates that too many LVs are used in the model and the noise is included to the model (Gomez et al., 2006; Min and Lee, 2005; Zou et al., 2007). SEC and SEP are calculated using Eqs. [1] and [2], respectively.

$\operatorname{SEC}(\%)=\sqrt{\frac{1}{I_{c}-n-1} \sum_{i=1}^{I_{c}}\left(\hat{y}_{i}-y_{i}\right)^{2}}$

$\operatorname{SEP}(\%)=\sqrt{\frac{1}{I_{p}-1} \sum_{i=1}^{I_{p}}\left(\hat{y}_{i}-y_{i}-\text { bias }\right)^{2}}$

\begin{tabular}{llcc}
\hline Cultivar & Color of the leaf & Duplicate & SPAD $_{\text {mean }}{ }^{2}$ \\
\hline C. sinensis cv. Jiukeng & Green, lucidus & 32 & 36.7 \\
C. sinensis cv. Biyun & Green & 30 & 31.4 \\
C. sinensis cv. Juhuaxiang & Kelly, lucidus & 31 & 42.9 \\
C. sinensis cv. Lvyafoshou & Pea green & 30 & 41.2 \\
C. sinensis cv. Meizhan & Bottle green, & 31 & 62.2 \\
C. sinensis cv. Zhenghedabaicha & Thick green, lucidus & 30 & 46.9 \\
\hline
\end{tabular}

${ }^{\mathrm{z}}$ The mean chlorophyll reading of all samples for each cultivar.

where $\hat{y}_{i}$-predicted value of the itch observation, $y_{i}$ measured the value of the $i$ th observation, $I_{c}=$ number of samples in the calibration set, $n=$ number of independent variables in calibration, $I_{p}=$ number of 
Table 2. Statistical parameters of chlorophyll index $(Y)$.

\begin{tabular}{lccccc}
\hline Sample sets & $\mathrm{SN}^{2}$ & Minimum & Maximum & Mean & SD \\
\hline Total samples & 184 & 26.8 & 75.9 & 43.494 & 10.844 \\
Calibration & 124 & 26.8 & 75.9 & 43.460 & 11.142 \\
Prediction & 60 & 29.1 & 68.6 & 43.778 & 10.231 \\
\hline
\end{tabular}

${ }^{\mathrm{z}}$ Sample number. samples in the validation/prediction set, and bias $=$ systematic difference between actual and predicted values calculated by formula

$$
\operatorname{bias}=\frac{1}{I_{p}} \sum_{i=1}^{I_{p}}\left(\hat{y}_{i}-y_{i}\right)
$$

\section{Results and Discussion}

Figure 1 shows typical absorbance spectra for the fresh tea leaves. All the samples of six cultivars had similar characteristics in absorbance spectral curves. From 400 to $500 \mathrm{~nm}$, the spectral curves were relatively flat and the absorbance values were at the highest level. After $500 \mathrm{~nm}$, spectral curves began to decrease until a "V" shape appeared at 550 $\mathrm{nm}$. From 550 to $675 \mathrm{~nm}$, the absorbance values increased along with the wavelength with a peak at $675 \mathrm{~nm}$. Then the spectral curve decreased again until the minimum was reached at $750 \mathrm{~nm}$. From 750 to $1000 \mathrm{~nm}$, the spectral curves were flat. It can be concluded that the leaf absorbed blue (400 to $500 \mathrm{~nm}$ ) and red $(680 \mathrm{~nm})$ light in the visible range, as reported in previous literature (Datt, 1999) and reflected NIR light (750 to $1000 \mathrm{~nm}$ ).

In Table 1, there are some differences in leaf color of these six cultivars. For example, the leaves of 'Meizhan' and 'Zhenghedabaicha' are greener than that of other cultivars. It can be found that the degree of greenness is generally consistent with the chlorophyll meter reading for cultivar; in other words, the cultivar with greener leaves usually has a higher chlorophyll reading. To develop a model with high adaptability, all the samples of the six cultivars were considered as a group for building the calibration model without building a model for each cultivar, although the diversity of samples from six cultivars provided some help for developing a model with good stability and high performance.

Considering the different spectral pretreatments, several calibration models were constructed based on the use of PLS. The results of these calibration models are summarized in Table 3 . In model 9, $r$ was very low and the values of SEC and SEP were much larger than that of the other models. This result indicated that the correlation between spectral characteristics and chlorophyll index was decreased by the second derivation spectral pretreatment. High-frequency noises in the spectra resulting from the reflectance mode in the field experiment could be magnified through the second derivation pretreatment (Candolfi et al., 1999; Zeaiter et al., 2005). The second derivation pretreatment was not suitable for these spectra.
Model 6 processed by offset correction was evaluated as the best model compared with other models (Table 3 ). The correlation coefficient of model 6 is the highest, the SEC and SEP values were smallest, and the difference between SEC and SEP values was relative small. The plots of predicted chlorophyll index versus reference chlorophyll index and their statistical summaries are shown in Figure 2. Compared with a similar study by $\mathrm{Hu}$ et al. (2006), the same conclusion that reflectance spectra was strongly correlated with chlorophyll index was obtained, but our results were better than that by $\mathrm{Hu}$ et al. (2006); their calibration model was obtained with $r$ of 0.7301 and root mean square error of prediction of 10.0781 .
The worse performance of model by Hu et al. (2006) may be caused by improper spectral pretreatment. The pretreatment method of second derivation used by $\mathrm{Hu}$ et al. (2006) had been proved to be an improper method for processing spectral data of tea leaves in this study.

To better understand the relationship between diffuse reflectance spectra and chlorophyll index, the individual wavelengths were analyzed. The optimum calibration model 6 was obtained based on nine LVs of PLS that contributed to the formation of the model. Table 4 shows the variation of each LV (LV1 to LV9). The first nine LVs accounted for the most variation of the whole original data with $97.997 \%$, and the good performance of model 6 proved that these LVs were closely correlated with the chlorophyll index. How the LV was constructed from the absorbance at entire individual wavelengths was demonstrated by the plot of LV loading in Figure 3, and the critical wavelengths for each LV could be detected. These wavelengths with small absolute loading
Table 3. Results of partial least squares models with different data pretreatment methods.

\begin{tabular}{|c|c|c|c|c|c|c|c|c|c|}
\hline \multirow[b]{2}{*}{ Model } & \multirow[b]{2}{*}{ Pretreatment } & \multirow[b]{2}{*}{ LV } & \multicolumn{3}{|c|}{ Calibration } & \multicolumn{4}{|c|}{ Prediction } \\
\hline & & & $r$ & SEC & Bias & $r$ & SEP & Bias & Dif $^{w}$ \\
\hline$\overline{1}$ & Smoothing $(3)^{\mathrm{z}}$ & 10 & 0.96 & 3.29 & $2.6 \mathrm{e}-06$ & 0.90 & 4.88 & 0.10 & 1.59 \\
\hline 2 & Smoothing $(5)^{z}$ & 10 & 0.95 & 3.45 & $-8.3 e-07$ & 0.89 & 4.95 & 0.07 & 1.50 \\
\hline 3 & Smoothing $(7)^{\mathrm{z}}$ & 4 & 0.88 & 5.33 & $-2.5 e-07$ & 0.86 & 5.73 & 0.02 & 0.40 \\
\hline 4 & Smoothing $(9)^{\mathrm{z}}$ & 4 & 0.87 & 5.33 & $-3.1 \mathrm{e}-07$ & 0.86 & 5.70 & 0.02 & 0.37 \\
\hline 5 & $\mathrm{SNV}^{\mathrm{y}}$ & 8 & 0.95 & 3.41 & $5.2 \mathrm{e}-07$ & 0.89 & 4.98 & 0.14 & 1.57 \\
\hline 6 & Offset correction & 9 & 0.95 & 3.40 & $1.9 \mathrm{e}-06$ & 0.91 & 4.77 & 0.02 & 1.37 \\
\hline 7 & $\operatorname{MSC}^{\mathrm{x}}$ & 2 & 0.85 & 5.84 & $-2.9 \mathrm{e}-07$ & 0.83 & 6.15 & 0.02 & 0.31 \\
\hline 8 & First derivatives & 4 & 0.93 & 4.02 & $-5.2 \mathrm{e}-07$ & 0.86 & 5.68 & 0.47 & 1.66 \\
\hline 9 & Second derivatives & 2 & 0.46 & 9.86 & $-1.7 \mathrm{e}-07$ & 0.26 & 10.96 & 0.41 & 1.10 \\
\hline
\end{tabular}

${ }^{\mathrm{z}}$ Smoothing $(\bullet)$ indicates that the spectrum is smoothed at $\bullet$ data point.

${ }^{\mathrm{y}}$ Standard normal variate.

${ }^{x}$ Multiplicative scatter correction.

wDifference between SEC and SEP.

$\mathrm{LV}=$ latent variable; $\mathrm{SEC}=\mathrm{SE}$ of calibration; $\mathrm{SEP}=\mathrm{SE}$ of prediction.

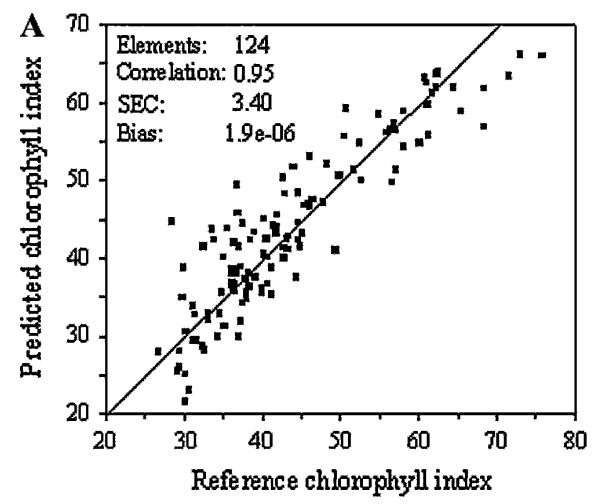

Full cross validation result

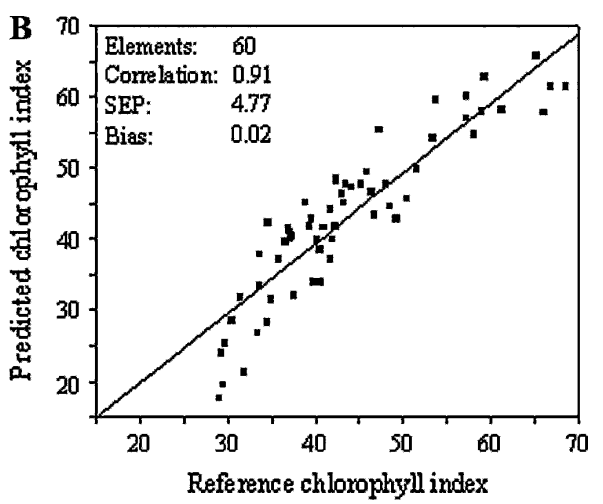

Prediction result
Fig. 2. Results of the optimum calibration model for determination of chlorophyll using partial least squares.

Table 4. Percentage variation explained by the nine latent variables in model 6.

\begin{tabular}{lcccccrrrr}
\hline LV $^{\mathrm{z}}$ & LV1 & \multicolumn{1}{c}{ LV2 } & \multicolumn{1}{c}{ LV3 } & \multicolumn{1}{c}{ LV4 } & \multicolumn{1}{c}{ LV5 } & \multicolumn{1}{c}{ LV6 } & \multicolumn{1}{c}{ LV7 } & \multicolumn{1}{c}{ LV8 } & LV9 \\
\hline $\mathrm{V}^{\mathrm{y}}(\%)$ & 74.25 & 17.884 & 3.614 & 0.278 & 0.602 & 0.397 & 0.306 & 0.297 & 0.369 \\
$\mathrm{TV}^{\mathrm{x}}(\%)$ & 74.25 & 92.134 & 95.748 & 96.026 & 96.628 & 97.025 & 97.331 & 97.628 & 97.997 \\
\hline
\end{tabular}

${ }^{\mathrm{z}}$ Latent variable.

y Variation.

${ }^{\mathrm{x}}$ Total variation. 

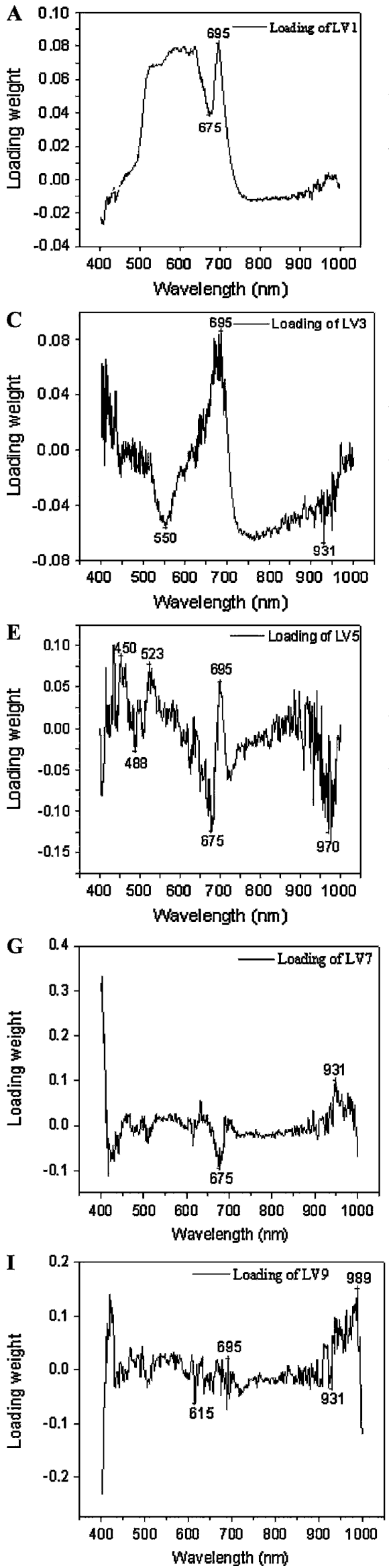

Fig. 3. Loading weights of the first nine latent variables (A-I) of the optimum calibration model using partial least squares.
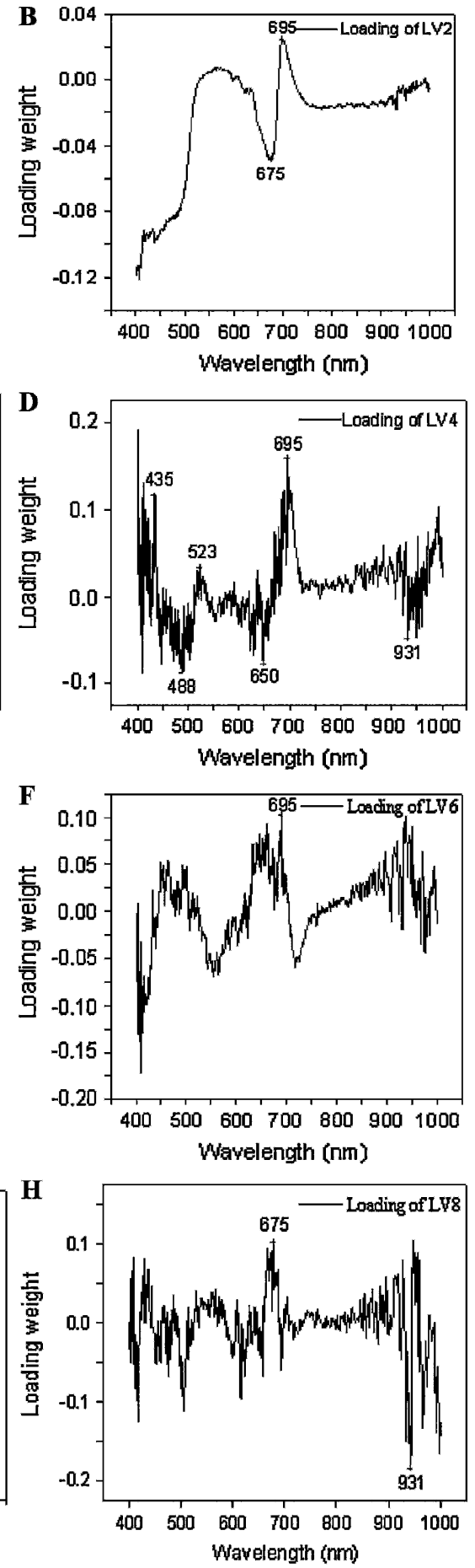
cant at $99 \%$ confidence level with three significant variables, $\mathrm{x}_{3}, \mathrm{x}_{9}$, and $\mathrm{x}_{10}$ (Table 6). The three corresponding wavelengths, 488, 695, and $931 \mathrm{~nm}$, were considered as the characteristic fingerprint spectra, which were strongly correlated with the chlorophyll index. The wavelength of $695 \mathrm{~nm}$ was the most significantly associated with chlorophyll determination. This spectral region had been found to be closely related to chlorophyll content in many plant species such as Chinese cabbage (Min et al., 2006), maple, chestnut, cotoneaster, tobacco (Gitelson and Merzlyak, 1998), eucalyptus (Datt, 1998), and loblolly pine (Carter and Knapp, 2001). The sensitive wavelength $488 \mathrm{~nm}$ was very close to the wavelength of $480 \mathrm{~nm}$ adopted for the determination of total $\mathrm{N}$ by Card et al. (1988). Chlorophyll of fresh tea leaves consists of chlorophyll a and chlorophyll b (Tong, 2000), and chlorophyll a and chlorophyll b mainly absorb light in the range of 400 to $500 \mathrm{~nm}$ and 660 to $690 \mathrm{~nm}$, respectively. These two ranges covered the two sensitive wavelengths (488 and $695 \mathrm{~nm}$ ) found in this study. Among these three sensitive wavelengths, two wavelengths (488 and $695 \mathrm{~nm}$ ) were in the visible band, and the lights in visible bands had been found 
to be effective for determination of chlorophyll by Yoder and Pettigrew-Crosby (1995). The wavelength of $931 \mathrm{~nm}$ was not reported as a sensitive wavelength for chlorophyll determination before, and it was contrary with the conclusion by Knipling (1970), in which they reported that reflectance in the NIR region was not correlated to leaf chlorophyll. However, the wavelength $(931 \mathrm{~nm})$ might actually be useful for chlorophyll determination of fresh tea leaves, because it was close to the third overtone absorptions band of methylene $\mathrm{C}-\mathrm{H}$ stretching vibration and methane $\mathrm{C}-\mathrm{H}$ stretching vibration (Cen and $\mathrm{He}, 2007)$.

The correlation coefficient $(r)$ for the MLR model was 0.89 and SEC was 5.13 (Fig. 4A). When the model was used to predict the unknown samples, a reasonable result was obtained with $r=0.86$ and SEP $=$ 5.36 (Fig. 4B). The performance of the MLR model was slightly worse than that of the optimal PLS model (Fig. 2). This phenomenon was not consistent with the conclusion by Siesler et al. (2002), in which they reported that MLR model with a few selected spectral variables would frequently outperform the PLS model with full spectral region. This phenomena might be caused by the fact that these diffuse reflectance spectra obtained in

Table 5. Analysis of variance table of the MLR model 10 based on all the 11 sensitive wavelengths.

\begin{tabular}{lcrcccc}
\hline Source of variance & \multicolumn{1}{c}{$\mathrm{SS}^{\mathrm{z}}$} & $\mathrm{DF}^{\mathrm{y}}$ & $\mathrm{MSS}^{\mathrm{x}}$ & F-ratio & $P$ value & B-coefficients \\
\hline Model & $1.24 \mathrm{E}+04$ & 11 & $1.13 \mathrm{E}+03$ & 44.197 & $<0.0001$ & \\
Error & $2.88 \mathrm{E}+03$ & 113 & 25.508 & & & \\
Adjusted total & $1.53 \mathrm{E}+04$ & 124 & 123.255 & & & \\
Variable intercept & 362.29 & 1 & 362.29 & 14.203 & 0.0003 & 17.374 \\
$\mathrm{x}_{1}$ & 55.557 & 1 & 55.557 & 2.178 & 0.1428 & 21.55 \\
$\mathrm{x}_{2}$ & 69.045 & 1 & 69.045 & 2.707 & 0.1027 & -32.485 \\
$\mathrm{X}_{3}$ & 232.23 & 1 & 232.23 & 9.104 & 0.0032 & -66.813 \\
$\mathrm{x}_{4}$ & 131.316 & 1 & 131.316 & 5.148 & 0.0252 & 95.019 \\
$\mathrm{X}_{5}$ & 83.691 & 1 & 83.691 & 3.281 & 0.0727 & -58.632 \\
$\mathrm{x}_{6}$ & $5.80 \mathrm{E}-03$ & 1 & $5.80 \mathrm{E}-03$ & $2.27 \mathrm{E}-04$ & 0.988 & 0.456 \\
$\mathrm{X}_{7}$ & 7.721 & 1 & 7.721 & 0.303 & 0.5833 & -12.632 \\
$\mathrm{X}_{8}$ & 26.023 & 1 & 26.023 & 1.02 & 0.3146 & 14.316 \\
$\mathrm{x}_{9}$ & 632.711 & 1 & 632.711 & 24.804 & $<0.0001$ & 89.355 \\
$\mathrm{x}_{10}$ & 428.385 & 1 & 428.385 & 16.794 & 0.0001 & -60.34 \\
$\mathrm{x}_{11}$ & $1.45 \mathrm{E}-02$ & 1 & $1.45 \mathrm{E}-02$ & $5.67 \mathrm{E}-04$ & 0.981 & 0.307 \\
\hline
\end{tabular}

${ }^{{ }^{2}}$ Sum of square.

${ }^{\mathrm{y}}$ Degree of freedom.

${ }^{\mathrm{x}}$ Mean sum of square.

$\mathrm{MLR}=$ multiple linear regression.

Table 6. Analysis of variance table of the MLR model 11.

\begin{tabular}{lcrcccr}
\hline Source of variance & \multicolumn{1}{c}{$\mathrm{SS}^{\mathrm{z}}$} & $\mathrm{DF}^{\mathrm{y}}$ & $\mathrm{MSS}^{\mathrm{x}}$ & F-ratio & $P$ value & B-coefficients \\
\hline Model & $1.22 \mathrm{E}+04$ & 3 & $4.07 \mathrm{E}+03$ & 158.961 & $<0.0001$ & \\
Error & $3.07 \mathrm{E}+03$ & 120 & 25.586 & & & \\
Adjusted total & $1.53 \mathrm{E}+04$ & 123 & 124.16 & & & \\
Variable intercept & 603.809 & 1 & 603.809 & 23.599 & $<0.0001$ & 16.642 \\
$\mathrm{x}_{3}$ & $4.55 \mathrm{E}+03$ & 1 & $4.55 \mathrm{E}+03$ & 177.669 & $<0.0001$ & -55.258 \\
$\mathrm{x}_{9}$ & $1.20 \mathrm{E}+04$ & 1 & $1.20 \mathrm{E}+04$ & 468.323 & $<0.0001$ & 114.428 \\
$\mathrm{x}_{10}$ & 3170 & 1 & $3.17 \mathrm{E}+03$ & 123.97 & $<0.0001$ & -64.012 \\
\hline
\end{tabular}

${ }^{\mathrm{z}}$ Sum of square.

${ }^{\mathrm{y}}$ Degree of freedom.

${ }^{\mathrm{x}}$ Mean sum of square.

MLR = multiple linear regression.

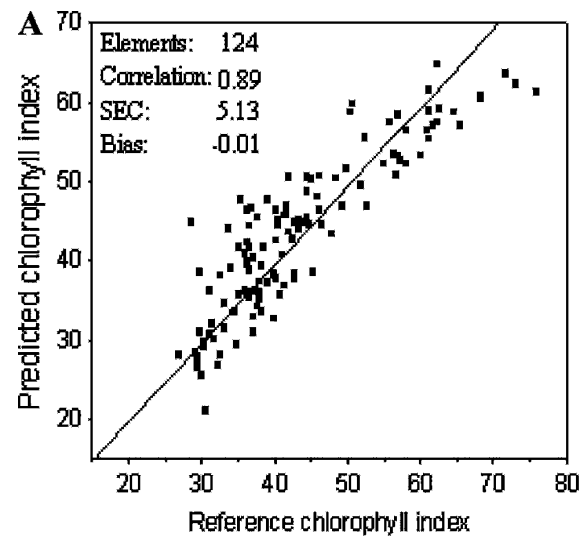

Validation result

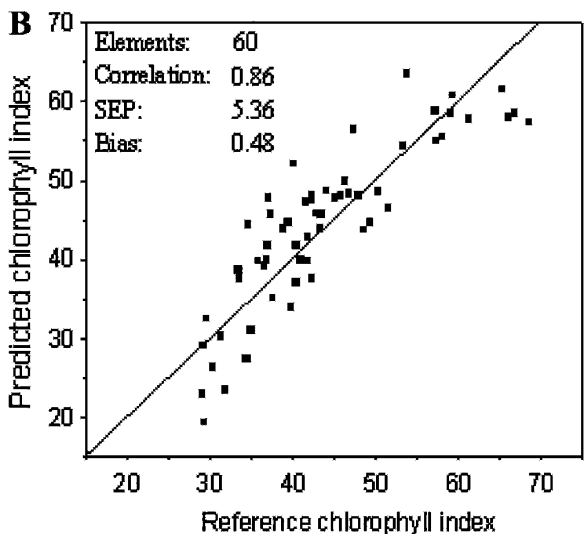

Prediction result
Fig. 4. Results of the calibration model using multiple linear regression and three fingerprint wavelengths. this field experiment were interfered with by serious noise and colinearity, and PLS arithmetic can compress data and reduce colinearity between variables (Helland, 2001; Min and Lee, 2005), so the PLS method obtained better performance than the MLR model. However, the MLR model was only based on three individual wavelengths and showed reasonable validity for determination of chlorophyll index, so MLR was also an effective technique for multivariate analysis. In addition, the PLS model provided an approach for wavelength selection that led to a better understanding of diffuse reflectance spectra; the loadings and loading weights of LVs for the PLS model gave the indication of a sensitive wavelength for the predicted $Y$.

The results showed that it was feasible to determine the chlorophyll index of the tea plant using reflectance spectral characteristics. The multivariable analysis techniques (PLS and MLR) had the potential to develop regression models for assessing chlorophyll index based on spectral data. The proper pretreatment could enhance the quality of the model by filtering the noise. The optimal PLS model was built with $r$ of 0.95 , the SEP of 3.40 , and a bias of $1.9 \mathrm{e}^{-06}$. The PLS model not only had high prediction accuracy, but also provided an approach for seeking the sensitive wavelengths. The MLR method was effective for selecting the most significant independent spectral variable using analysis of variance and achieved a reasonable result for determination of the chlorophyll index. Three individual sensitive wavelengths (488, 695 , and $931 \mathrm{~nm}$ ) were determined for the measurement of chlorophyll index and could potentially be used for developing a simple, low-cost, and efficient instrument.

\section{Literature Cited}

Abdelhamid, M., T. Horiuchi, and S. Oba. 2003. Evaluation of the SPAD value in faba bean (Vicia faba L.) leaves in relation to different fertilizer applications. Plant Prod. Sci. 6:185-189.

Bausch, W.C. and H.R. Duke. 1996. Remote sensing of plant nitrogen status in corn. Trans. ASAE 39:1869-1875.

Candolfi, A., R. De Maesschalck, D. JouanRimbaud, P.A. Hailey, and D.L. Massart 1999. The influence of data pre-processing in the pattern recognition of excipients nearinfrared spectra. J Pharm. 21:115-132.

Card, D.H., D.L. Peterson, P.A. Matson, and J.D. Aber. 1988. Prediction of leaf chemistry by the use of visible and near-infrared reflectance spectroscopy. Remote Sens. Environ. 26:123-147.

Carter, G.A. and A.K. Knapp. 2001. Leaf optical properties in higher plants: Linking spectral characteristics to stress and chlorophyll concentration. Amer. J. Bot. 88:677-684.

Castelli, F., R. Contillo, and F. Miceli. 1996. Nondestructive determination of leaf chlorophyll content in four crop species. J. Agron. Crop Sci. 177:275-283.

Cen, H. and Y. He. 2007. Theory and application of near infrared reflectance spectroscopy in determination of food quality. Trends Food 18: $72-83$.

Chang, S.X. and D.J. Robison. 2003. Nondestructive and rapid estimation of hardwood foliar 
nitrogen status using the SPAD-502 chlorophyll meter. Forest Ecol. 181:331-338.

Chen, C.T., S. Chen, K.W. Hsieh, H.C. Yang, S. Hsiao, and I.C. Yang. 2004. Estimation of Nitrogen content by spectral responses of cabbage seedlings using artificial neural network approach. ASAE/CSAE Annual International Meeting sponsored by ASAE/CSAE Fairmont Chateau Laurier, The Westin, Government Centre Ottawa, Ontario, Canada, 1-4 Aug. 2004. Paper number: 041082.

Datt, B. 1998. Remote sensing of chlorophyll a, chlorophyll $\mathrm{b}$, chlorophyll $\mathrm{a}+\mathrm{b}$, and total carotenoid content in eucalyptus leaves. Remote Sens. Environ. 66:111-121.

Datt, B. 1999. A new reflectance index for remote sensing of chlorophyll content in higher plants: Tests using eucalyptus leaves. J. Plant Physiol. 154:30-36.

Daughtry, C.S.T., C.L. Walthall, M.S. Kim, E.B. de Colstoun, and J.E. McMurtrey. 2000. Estimating core leaf chlorophyll concentration from leaf and canopy reflectance. Remote Sensing of Environment 74:229-239.

Gitelson, A.A. and M.N. Merzlyak. 1998. Remote sensing of chlorophyll concentration in higher plant leaves. Adv. Space Res. 22:689692.

Gomez, A.H., Y. He, and A.G. Pereira. 2006. Nondestructive measurement of acidity, soluble solids and firmness of Satsuma mandarin using Vis/NIR-spectroscopy technique. J. Food Eng. 77:313-319.

Helland, I.S. 2001. Some theoretical aspects of partial least squares regression. Chem. Intell. 58:97-107.

Hu, Y., P. Li, H. Mao, B. Chen, and Y. Ding. 2006. Spectral reflectance-based detection of nitrogen content in fresh tea leaves. Proc. of SPIE. 6411:64110G1-64110G8.

Ishikawa, D., I. Etsuji, S.I. Sekioka, T. Okamoto, A. Nesumi, and K. Oba. 2006. Development of yield and quality estimation methods for teaplant by image processing. Proc. of ASACSSA-SSSA Annual Meeting. p. 43-44.

Karimi, Y., S.O. Prasher, H. McNairn, R.B. Bonnell, P. Dutilleul, and P.K. Goel. 2005. Discriminant analysis of hyperspectral data for assessing water and nitrogen stresses in corn. Trans. ASAE 48:805-813.

Knipling, E.B. 1970. Physical and physiological basis for the reflectance of visible and nearinfrared radiation from vegetation. Remote Sens. Environ. 1:155-159.

Lammertyn, J., B. Nicolaï, K. Ooms, V. De Smedt, and J. De Baerdemaeker. 1998. Non-destructive measurement of acidity, soluble solids, and firmness of Jonagold apples using NIR-spectroscopy. Trans. ASAE 41:1089-1094.

Lattin, J.M., J. Douglas, and P.E. Green. 2003. Analyzing multivariate data. China Machine Press, Beijing, China.

Loh, F.C.W., J.C. Grabosky, and N.L. Bassuk. 2002. Using the SPAD-502 meter to assess chlorophyll and nitrogen content of benjamin fig and cottonwood leaves. Hort Technology 12:682-686.

Madan, J., A.K. Dwivedi, and S. Singh. 2005. Estimation of antitubercular drugs combination in pharmaceutical formulations using multivariate calibration. Anal. Chim. Acta 538:345-353.

Min, M. and W.S. Lee. 2005. Determination of significant wavelengths and prediction of nitrogen content for citrus. Trans. ASAE 48:455-461.

Min, M., W.S. Lee, Y.H. Kim, and R.A. Bucklin. 2006. Nondestructive detection of nitrogen in Chinese cabbage leaves using VIS-NIR spectroscopy. HortScience 41:162-166.

Pinkard, E.A., V. Patel, and C. Mohammed. 2006. Chlorophyll and nitrogen determination for plantation-grown Eucalyptus nitens and E. globules using a non-destructive meter. Forest Ecol. 223:211-217.

Schaper, H. and E.K. Chacko. 1991. Relation between extractable chlorophyll and portable chlorophyll meter readings in leaves of eight tropical and subtropical fruit tree species. J. Plant Physiol. 138:674-677.

Siesler, H.W., Y. Ozaki, S. Kawata, and H. Michael Heise. 2002. Near-infrared spectroscopy: Principle, instrument, applications. Wiley-VCH, Weinheim, Germany.

Song, X.Z., Y.J. Zhao, J.F. Zhang, P. Liu, and J.H. Chen. 2002. Relationship between chlorophyll meter readings (SPAD readings) and chlorophyll content of tea leaves. Shandong Forestry Science and Technology 6:10-12. (in Chinese).
Takebe, M., T. Yoneyama, K. Inada, and T. Murakami. 1990. Spectral reflectance ratio of rice canopy for estimating crop nitrogen status. Plant Soil 122:295-297.

Tong, Q.Q. 2000. Tea cultivation. 3rd Ed. Agriculture Publishers, Beijing, China.

Tumbo, S.D., D.G. Wagner, and P.H. Heinemann. 2002. Hyperspectral characteristics of corn plants under different chlorophyll levels. Trans. ASAE 45:815-823.

Ulson, J.A.C., R.L.V. Boas, L.J.G. Godoy, and A. N. de Souza. 2002. A novel intelligent system to nitrogen content prediction in plants using indirect chlorophyll measurements, p. 29-35. In: Zazueta, F.S. and Xin, J. (Eds.). In: Proc. of the World Congress of Computers in Agriculture and Natural Resources, 13-15 March 2002, Iguacu Falls, Brazil.

van den Berg, A.K. and T.D. Perkins. 2004. Evaluation of a portable chlorophyll meter to estimate chlorophyll and nitrogen contents in sugar maple leaves. Forest Ecol. 200:113117.

Williams, P. and K. Norris. 2001. Near-infrared technology in the agricultural and food industries. 2nd Ed. American Association of Cereal Chemists, St. Paul, MN.

Yamamoto, A., T. Nakamura, J.J. Adu-Gyamfi, and M. Saiqusa. 2002. Relationship between chlorophyll content in leaves of sorghum and pigeon pea determined by extraction method and by chlorophyll meter (SPAD-502). J. Plant Nutr. 25:2295-2301.

Yoder, B.J. and R.E. Pettigrew-Crosby. 1995. Predicting nitrogen and chlorophyll content and concentrations from reflectance spectra (400-2500 nm) at leaf and canopy scales. Remote Sens. Environ. 53:199-211.

Zeaiter, M., J.M. Roger, and V. Bellon-Maurel. 2005. Robustness of models developed by multivariate calibration. Part II: The influence of pre-processing methods. TRAC-Trends 24:437-445.

Zou, X.B., J.W. Zhao, X.Y. Huang, and Y.X. Li. 2007. Use of FT-NIR spectrometry in noninvasive measurement of soluble solid contents (SSC) of 'Fuji' apple based on different PLS models. Chem. Intell. 87:43-51. 